\title{
Removal of beneficial insertion effects prevent the long-term persistence of transposable elements within simulated asexual populations
}

\author{
Christopher L. Butler* (D), Ellen A. Bell and Martin I. Taylor
}

\begin{abstract}
Background: Transposable elements are significant components of most organism's genomes, yet the reasons why their abundances vary significantly among species is poorly understood. A recent study has suggested that even in the absence of traditional molecular evolutionary explanations, transposon proliferation may occur through a process known as 'transposon engineering'. However, their model used a fixed beneficial transposon insertion frequency of $20 \%$, which we believe to be unrealistically high.

Results: Reducing this beneficial insertion frequency, while keeping all other parameters identical, prevented transposon proliferation.

Conclusions: We conclude that the author's original findings are better explained through the action of positive selection rather than 'transposon engineering', with beneficial insertion effects remaining important during transposon proliferation events.
\end{abstract}

Keywords: Transposon proliferation, Genome ecology, Positive selection, C-value, In-silico model

\section{Background}

Transposable elements (TEs) are short regions of noncoding DNA (100-10,000 bp) which can proliferate throughout a genome, and are significant genomic components of a taxonomically diverse range of species [1-3]. Understanding the processes which drive TE variation across different species is an important goal in answering the so-called ' $\mathrm{C}$-value' paradox (the observed lack of relationship between genome size and organismal complexity) [4]. TEs are thought to accumulate within a population through a number of evolutionary mechanisms which include (i) positive selection, (ii) genetic drift,

*Correspondence: c.butler@uea.ac.uk

This comment refers to the article available online at https://doi.org/10.1186/ s12864-020-6763-1

School of Biological Sciences, University of East Anglia, Norwich Research Park, NR4 7TJ, Norwich, UK (iii) co-evolution with the host, (iv) sexual recombination or (v) horizontal transfer. Kremer et al. [5] investigated the fate of TE populations where none of these population genetic scenarios were possible [5]. Using in-silico modelling, the authors established an asexual population where (i) TE insertions had serious negative effects on host fitness, (ii) TEs could not evolve insertion site preferences (i.e. no co-evolution with the host) and (iii) TEs were not able to be horizontally transferred. Surprisingly, even in the absence of these evolutionary forces, TEs accumulated in a limited number (3\%) of scenarios. The authors concluded that these rare accumulation events may be explained through 'TE engineering'; a process in which the activity of TEs significantly alters the landscape of a genome to facilitate further proliferation. Specifically, they suggest that the cycle of TE proliferation and degradation

(c) The Author(s). 2021 Open Access This article is licensed under a Creative Commons Attribution 4.0 International License, which permits use, sharing, adaptation, distribution and reproduction in any medium or format, as long as you give appropriate credit to the original author(s) and the source, provide a link to the Creative Commons licence, and indicate if changes were made. The images or other third party material in this article are included in the article's Creative Commons licence, unless indicated otherwise in a credit line to the material. If material is not included in the article's Creative Commons licence and your intended use is not permitted by statutory regulation or exceeds the permitted use, you will need to obtain permission directly from the copyright holder. To view a copy of this licence, visit http://creativecommons.org/licenses/by/4.0/. The Creative Commons Public Domain Dedication waiver (http://creativecommons.org/publicdomain/zero/1.0/) applies to the data made available in this article, unless otherwise stated in a credit line to the data. 
may provide new non-coding regions in which future TEs can insert with little or no consequence on host fitness. Changes in TE abundance which occur through their interactions with either the host genome or other transposons comprise a poorly studied field known as 'TE ecology' $[6,7]$. Consequently, Kremer et al. [5] appears to have identified a novel mechanism for TE proliferation, with important implications regarding our understanding of TE dynamics.

Here, we highlight some potential issues which question the key findings of Kremer et al's study. They claim that their simulations model TE insertions which do not have any beneficial effects on host fitness; crucially ruling out positive selection as an explanation for TE accumulation. However, there was a lack of clarity on the precise meaning of 'no beneficial effects', with three explanations on the effects of TE insertions given in their paper. These were: (i) 'TEs had a net deleterious effect on host fitness', (ii) TEs had 'serious negative effects on host fitness' or, (iii) 'violated the assumption that TE insertions are beneficial'. A model in which TE activity had a net deleterious effect could mean that only a very small majority of TE insertions reduce host fitness. Such a model would violate the author's own assumption that TE insertions cannot be beneficial, with fitness increases still occurring during a significant number of insertions. Greater clarity on this issue would have been beneficial in order to help validate the legitimacy of Kremer et al's conclusions.

The final model used in Kremer et al. [5] included a fixed parameter which simulates a mildly beneficial fitness effect (Insertion_effect) during 20\% of all TE insertions. Crucially, setting an insertion benefit at this level is not consistent with the author's own conclusion that positive selection is not responsible for driving the TE accumulation events observed. Theoretically, the level of beneficial TE insertions may not have to be very high for their gradual accumulation. The fact that original TE copies are frequently retained in the genome (i.e. progeny distribution $>1$ ) can provide a buffer to their abundance, even if the majority of new insertions are deleterious. This has been demonstrated in other simple TE dynamic models, whereby increasing the adaptive insertion probability to $0.05 \%$ is sufficient to permit TE domestication through positive selection [8]. In this study, we repeated Kremer et al's [5] simulations, but explicitly defined 'no beneficial insertion effect' to mean there was no scenario in which TE insertions could generate an increase in host fitness, thus definitely ruling out positive selection as a potential mechanism for TE proliferation.

\section{Methods}

To test whether removing the positive TE insertion effect altered their ability to accumulate, we reanalysed the six parameter scenarios from Kremer et al. [5] where in the majority of cases TEs persisted for the 1,500 generation cut off set by the authors (Table 1). We did not change the percentage of TE insertions which led to lethal deleterious $(20 \%)$ or mildly deleterious $(30 \%)$ fitness effects. Instead we increased the probability that a TE insertion was neutral (i.e generating no change in host fitness) from $30 \%$ to $50 \%$. All other model parameters remained identical. Following Kremer et al., we then repeated each simulation three times independently, which were plotted using the 'ggplot2' package in R v3.5.1 [9].

\section{Results}

In our reanalysis, we found that across each of the six parameter scenarios, TEs were better able to accumulate when the model included a beneficial TE insertion effect (Fig. 1). Indeed, in the 18 iterations we ran, TEs only accumulated in a single instance when the beneficial insertion effects were removed (Run 3 of LLLH-LHHL). We also investigated the frequency of beneficial TE insertions that would be required for TE accumulation. To do this, we chose a parameter scenario in which Kremer et al. found TEs to accumulate in every run (namely LLLH-LLHH). When the beneficial TE insertion effect was reduced to 0 (from 20\%), the TE population did not proliferate, becoming extinct in under 400 generations in every iteration. We also ran simulations where TE insertions increased host fitness $1 \%, 5 \%, 10 \%$ and $15 \%$ of the time. While this led to incremental increases in TE accumulation, none of the simulations lasted 1,500 generations (Fig. 2). We therefore conclude that under this TE dynamic model, a significant positive insertion effect is required for TE accumulation in almost all cases.

\section{Discussion}

Overall, our findings suggest that Kremer et al's [5] key conclusion of TE accumulation in a significant number of cases can largely be explained by the high beneficial insertion frequency used by the authors. When we removed this effect, TEs did not persist in the overwhelming majority of scenarios. We therefore suggest that the author's original finding of TE accumulation would have been better explained by the action of positive selection instead of a 'TE engineering' process. The $20 \%$ beneficial insertion effect set by the authors is likely to be a significant overestimate compared to what may be observed in reality. Whilst estimating the frequency of beneficial insertion effects remains difficult, a recent genome-wide scan of 14,384 human TE polymorphisms concluded that just 1.13\% (163) were under positive selection [10]. The true frequency of beneficial TE insertions is likely to be even lower, as many highly deleterious or neutral TEs will lie undetected as they are removed from the genome. Interestingly, we did identify a single combina- 
Table 1 The parameter scenarios where Kremer et al. [5] reported TE accumulation in the majority of cases

\begin{tabular}{|c|c|c|c|c|c|c|c|c|}
\hline \multicolumn{4}{|c|}{ TE Properties } & \multicolumn{4}{|c|}{ Host Properties } & \multirow[t]{2}{*}{ Parameter Scenaric } \\
\hline $\begin{array}{l}\text { TE } \\
\text { Progeny }\end{array}$ & $\begin{array}{l}\text { TE Excision } \\
\text { Rate }\end{array}$ & $\begin{array}{l}\text { TE Death } \\
\text { Rate }\end{array}$ & $\begin{array}{l}\text { Insertion } \\
\text { Bias }\end{array}$ & $\begin{array}{l}\text { Corrected } \\
\text { Mutation } \\
\text { Rate }\end{array}$ & $\begin{array}{l}\text { Non-Coding } \\
\text { DNA }\end{array}$ & $\begin{array}{l}\text { Mutation } \\
\text { Effect }\end{array}$ & $\begin{array}{l}\text { Carrying } \\
\text { Capacity }\end{array}$ & \\
\hline High & Low & Low & Low & Low & High & Low & High & HLLL - LHLH \\
\hline Low & Low & High & High & Low & High & High & High & LLHH - LHHH \\
\hline Low & Low & Low & High & Low & High & High & Low & LLLH - LHHL \\
\hline Low & Low & Low & High & Low & Low & High & High & LLLH - LLHH \\
\hline Low & Low & Low & Low & Low & High & High & High & LLLL - LHHH \\
\hline Low & Low & Low & Low & Low & Low & High & Low & LLLL - LLHL \\
\hline
\end{tabular}

tion of parameters in which TEs did accumulate without exhibiting any beneficial fitness effect; namely when TE progeny and excision rate is low, TEs display high insertion bias, and the degree of non-coding regions in the genome are high. This may provide an interesting avenue for understanding genomic characteristics where TEs may accumulate in the absence of positive selection. Many TEs display both an insertion site bias $[11,12]$ and variable TE activity rates (a product of both TE excision and progeny rates) within the lifetime of a cell [13]. Finally, we wish to emphasise that we are not suggesting that TE ecology explanations should be ruled out when trying to understand the reasons for TE accumulation. On the contrary, when exploring potential hypotheses for TE proliferation it is important to realise that both evolutionary and ecology processes are likely to occur concurrently.

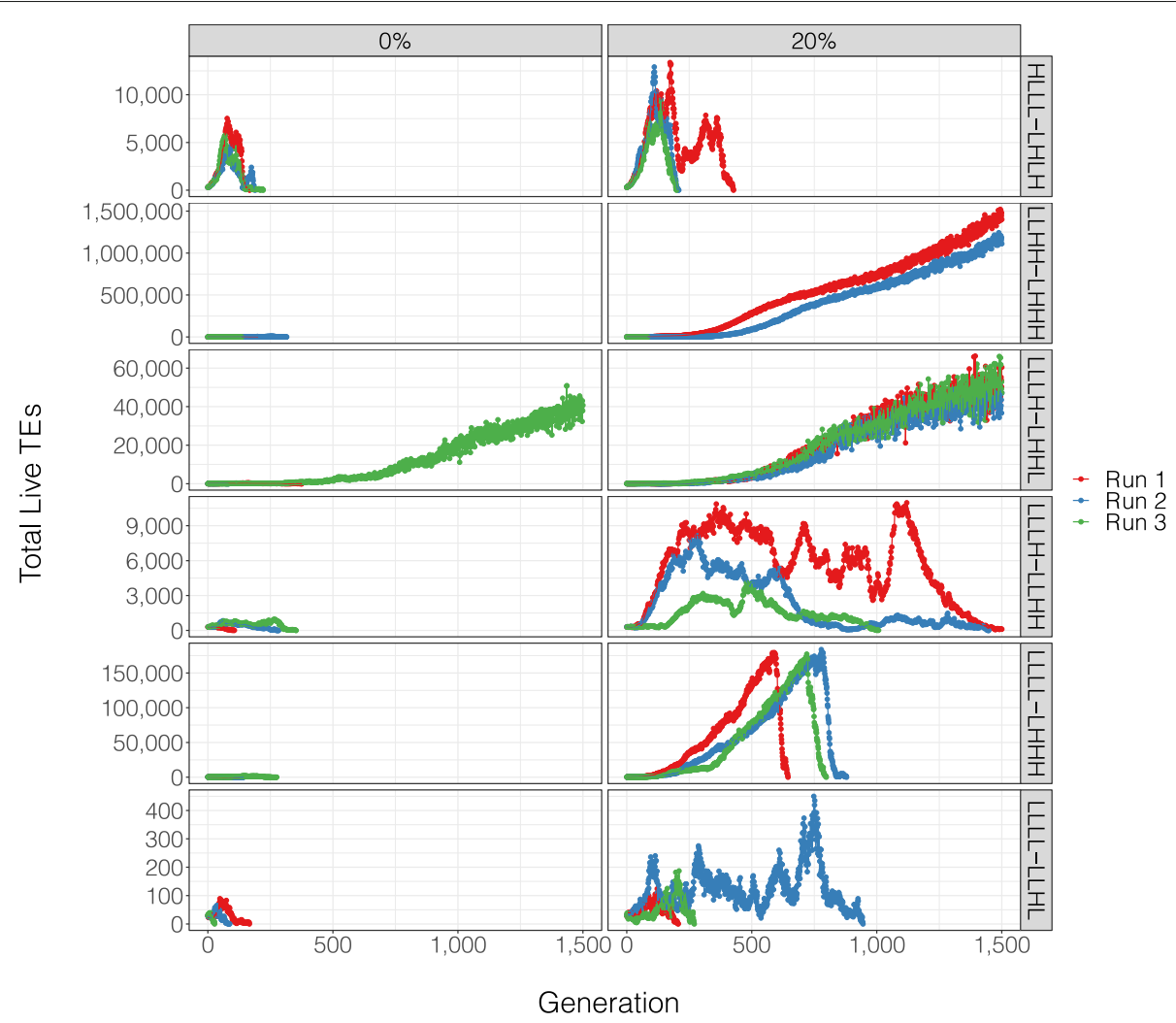

Fig. 1 TE population dynamics for each of the six parameters where Kremer et al. [5] reported TE accumulation in the majority of cases. Beneficial TE insertions were set at either $0 \%$ or $20 \%$. When beneficial insertion effects were excluded from the model, TEs failed to proliferate in all but one case (Run 3 of LLLH-LHHL) 


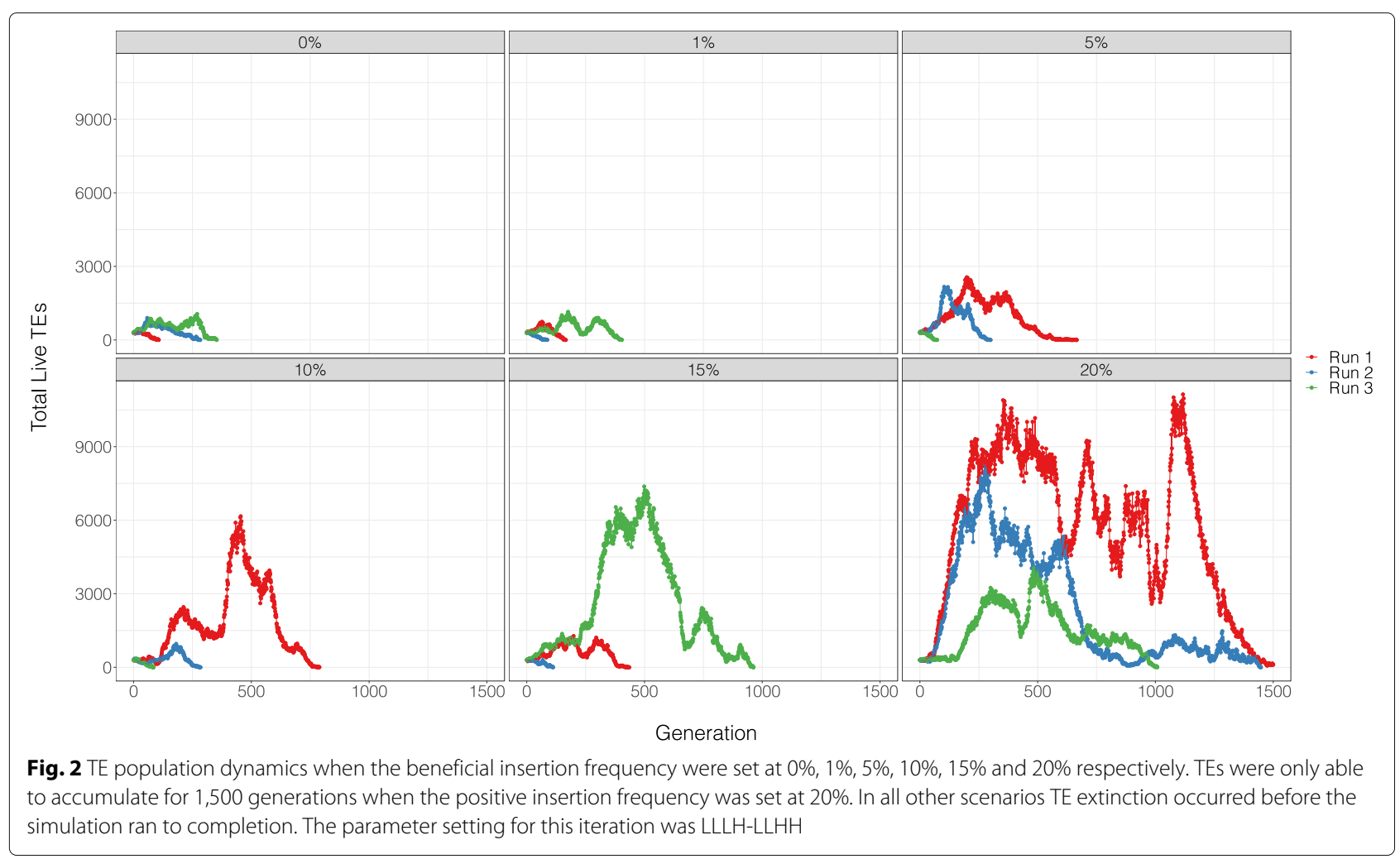

\section{Abbreviations}

TE; Transposable element

Acknowledgements

Not applicable.

\section{Authors' contributions}

The study was conceived by CB, EB \& MT. Analysis was conducted by CB. The final manuscript was written by CB, EB \& MT. All authors read and approved the final manuscript.

\section{Funding}

CB was supported by a Natural Environment Research Council (NERC) and EnvEast doctoral training partnership (DTP) grant [grant number NE/L002582/1] and EB was supported by a BBSRC grant [BB/R017174/1] awarded to MT. The funders had no role in the design of the study, analysis, interpretation of the data or the writing of the manuscript.

\section{Availability of data and materials}

The datasets analysed during this study were generated using the TE_World2 model, which can be accessed at: https://github.com/stefan-c-kremer/TE_ World2 [5].

\section{Declarations}

Ethics approval and consent to participate Not applicable.

\section{Consent for publication}

Not applicable.

\section{Competing interests}

The authors declare that they have no competing interests.
Received: 24 July 2020 Accepted: 30 March 2021

Published online: 07 April 2021

\section{References}

1. Chénais B, Caruso A, Hiard S, Casse N. The impact of transposable elements on eukaryotic genomes: From genome size increase to genetic adaptation to stressful environments. Gene. 2012;509(1):7-15. https://doi. org/10.1016/J.GENE.2012.07.042.

2. Chalopin D, Naville M, Plard F, Galiana D, Volff J-N. Comparative analysis of transposable elements highlights mobilome diversity and evolution in vertebrates,. Genome Biol Evol. 2015;7(2):567-80. https://doi.org/10.1093/ gbe/evv005.

3. Sotero-Caio CG, Platt RN, Suh A, Ray DA, Ray DA. Evolution and diversity of transposable elements in vertebrate genomes. Genome Biol Evol. 2017;9(1):161-77. https://doi.org/10.1093/gbe/evw264.

4. Elliott TA, Gregory TR. What's in a genome? The C-value enigma and the evolution of eukaryotic genome content. Philos Trans R Soc B Biol Sci. 2015;370(1678):20140331. https://doi.org/10.1098/rstb.2014.0331.

5. Kremer SC, Linquist S, Saylor B, Elliott TA, Gregory TR, Cottenie K. Transposable element persistence via potential genome-level ecosystem engineering. BMC Genomics. 2020;21 (1):367. https://doi.org/10.1186/ s12864-020-6763-1.

6. Brookfield JFY. The ecology of the genome - Mobile DNA elements and their hosts. Nat Rev Genet. 2005;6(2):128-36. https://doi.org/10.1038/ nrg1524.

7. Venner S, Feschotte C, Biémont C. Dynamics of transposable elements: towards a community ecology of the genome. Trends Genet. 2009;25(7): 317-23. https://doi.org/10.1016/j.tig.2009.05.003.

8. Le Rouzic A, Boutin TS, Capy P. Long-term evolution of transposable elements. Proc Natl Acad Sci U S A. 2007;104(49):19375-80.

9. Wickham H. ggplot2: elegant graphics for data analysis. New York: Springer; 2016. https://ggplot2.tidyverse.org.

10. Rishishwar L, Wang L, Wang J, Yi SV, Lachance J, Jordan IK. Evidence for 
positive selection on recent human transposable element insertions. Gene. 2018;675:69-79. https://doi.org/10.1016/j.gene.2018.06.077.

11. Sultana T, Zamborlini A, Cristofari G, Lesage P. Integration site selection by retroviruses and transposable elements in eukaryotes. Nat Rev Genet. 2017;18(5):292-308. https://doi.org/10.1038/nrg.2017.7.

12. Bourque G, Burns KH, Gehring M, Gorbunova V, Seluanov A, Hammell M, Imbeault M, Izsvák Z, Levin HL, Macfarlan TS, Mager DL, Feschotte C. Ten things you should know about transposable elements. Genome Biol. 2018;19(1):199. https://doi.org/10.1186/s13059-018-1577-z.

13. Kim NH, Lee G, Sherer NA, Martini KM, Goldenfeld N, Kuhlman TE, Austin RH, Lippincott-Schwartz J, Phillips R. Real-time transposable element activity in individual live cells. Proc Natl Acad Sci U S A. 2016;113(26):7278-83. https://doi.org/10.1073/pnas.1601833113.

\section{Publisher's Note}

Springer Nature remains neutral with regard to jurisdictional claims in published maps and institutional affiliations.

- fast, convenient online submission

- thorough peer review by experienced researchers in your field

- rapid publication on acceptance

- support for research data, including large and complex data types

- gold Open Access which fosters wider collaboration and increased citations

- maximum visibility for your research: over $100 \mathrm{M}$ website views per year

At BMC, research is always in progress.

Learn more biomedcentral.com/submissions 